\title{
Bioremediation of oxytetracycline in seawater by living and dead biomass of the microalga Phaeodactylum tricornutum
}

\author{
Sergio Santaeufemia, Enrique Torres*, Roi Mera, Julio Abalde \\ Laboratorio de Microbiología, Facultad de Ciencias, Universidade da Coruña. Campus da Coruña. 15071A \\ Coruña, Spain
}

Journal of Hazardous Materials, Volume 320, 15 December 2016, Pages 315-325

Received 10 June 2016, Revised 12 August 2016, Accepted 15 August 2016, Available online 16 August 2016

\section{How to cite}

S. Santaeufemia, E. Torres, R. Mera, J. Abalde, Bioremediation of oxytetracycline in seawater by living and dead biomass of the microalga Phaeodactylum tricornutum, J. Hazard. Mater. 320(2016) 315-325. doi: 10.1016/j.jhazmat.2016.08.042

\section{Highlights}

- $\quad$ Living and dead biomass of $P$. tricornutum is able to eliminate OTC from seawater.

- The most effective and efficient OTC elimination was achieved with living biomass.

- Living biomass of $P$. tricornutum showed a maximum sorption capacity of $29.18 \mathrm{mg} \mathrm{g}^{-1}$.

- Culture of P. tricornutum allowed to combine bioremediation with photodegradation.

\begin{abstract}
Due to its use, a large amount of Oxytetracycline (OTC) is released into water, which has a detrimental impact on aquatic ecosystems and human health. Although there are different physicochemical methods (mainly photodegradation) to remove OTC, there is increasing interest in the use of bioremediation. The sorption characteristics of OTC using living and dead biomass of the microalga Phaeodactylum tricornutum have been investigated in this study. Kinetics, isotherms and maximum elimination capacity were tested and discussed. Kinetic studies showed that the OTC removal by living biomass followed a sigmoidal model. However, the dead biomass followed a pseudo-first order model. The living biomass showed higher efficiency than the dead biomass with maximum sorption capacities of $29.18 \mathrm{mg} \mathrm{g}^{-1}$ and
\end{abstract}


$4.54 \mathrm{mg} \mathrm{g}^{-1}$, respectively. Combination of living biomass and photodegradation under the culture conditions eliminated $13.2 \mathrm{mg} \mathrm{L}^{-1}$ of OTC during $11 \mathrm{~h}$ of culture and with an initial OTC concentration of $15 \mathrm{mg} \mathrm{L}^{-1}$. With an initial OTC concentration of $2.5 \mathrm{mg} \mathrm{L}^{-1}$, 97\% of OTC was removed. This removal was mainly caused by bioremediation than by photodegradation. The results proved the potential practical application of the living $P$. tricornutum biomass for a low-cost and efficient removal of OTC from seawater.

\section{Graphical abstract}

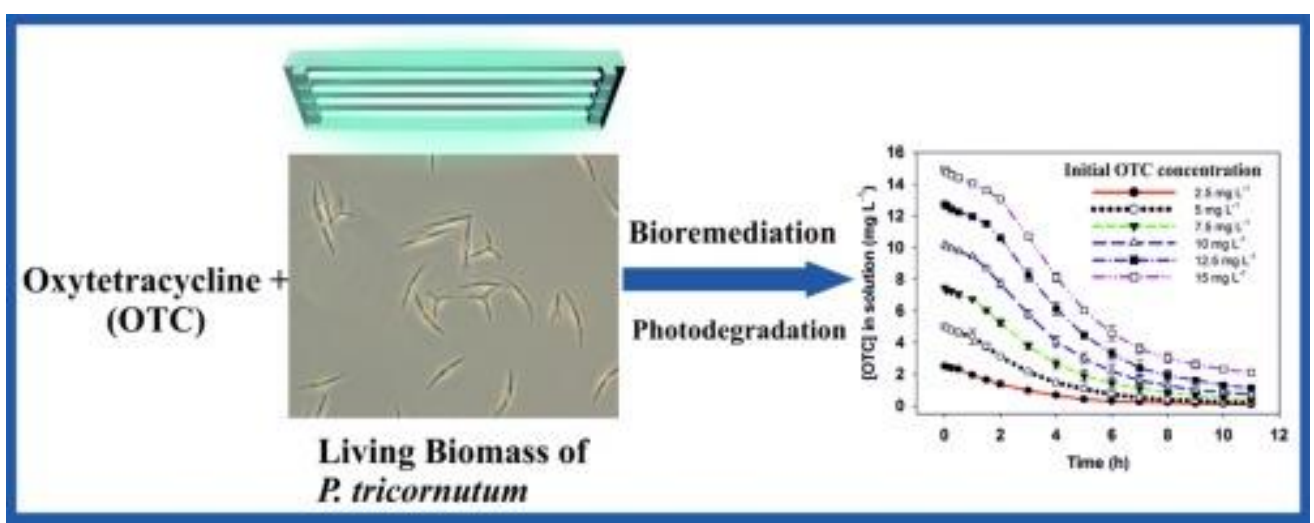

\section{Keywords}

Oxytetracycline; Phaeodactylum tricornutum; Bioremediation; Living biomass; Sorption

\section{INTRODUCTION}

There is increasing concern about the adverse effects of antibiotics in aquatic environments since they are widely used in medicine, industrial agriculture and aquaculture. In this latter case, the rapid development of fish farming has led to an increased use of antibiotics to prevent diseases. In fish farming, antibiotics can be administered directly into the waters or be incorporated in the diet and subsequently excreted to the environment as faeces or urine [1]. In this case, as being poorly metabolized, these compounds are released to the environment almost entirely [2]. This uncontrolled discharge of antibiotics presents a number of significant drawbacks, causing damage to aquatic ecosystems and development of bacterial resistance [3] and [4]. For this reason, they are included within the so-called emerging pollutants. This reflects a clear need to create and develop effective treatments to remove these compounds from aquatic media.

Tetracyclines (TCs) are one of the most important antibiotics that exhibit activity against most Gram positive and negative bacteria. Within the TCs, oxytetracycline (OTC) is the most used around the world for its high efficiency and low cost [5] and [6]. OTC is widely used in fish farms where its concentration in effluents can be high [7], [8] and [9]. Therefore, OTC constitutes a serious environmental problem. 
There are various treatments to remove TCs from water, such as oxidation [10], electrodegradation [11] and photocatalytic degradation [12] and [13]. The problem with these techniques is that most of them are little effective or can cause adverse effects on the environment due to the production of by-products. The photolytic degradation is the most used technique for OTC elimination, and in most cases is used in combination with other treatments [14] and [15]. Thus, the OTC stability in seawater was previously described by Tore Lunestad et al. [16]. These authors found that OTC reduced its antimicrobial activity when exposed to underwater light intensities for a period of $21 \mathrm{~d}$. Pouliquen et al. [14] found that the photolysis was responsible for about $70 \%$ of the OTC degradation in seawater during $14 \mathrm{~d}$ of exposure. More recently, Leal et al. [17] studied the possibility to apply the solar photodegradation for OTC removal. These authors showed that for a midsummer day, at sea level, the outdoor half-life time predicted for OTC in aquaculture's waters ranged between 21 and $25 \mathrm{~min}$.

However, it is important to explore new technologies to remove this type of pollutants in a more efficient and less harmful way. An alternative is the use of a material as sorbent of contaminants. In this sense, various sorbents have been used to remove TCs; for example, sorbents derived from sludge [18], montmorillonite [19], graphene oxide [20], clay [21], carbon nanotubes [22] and even activated carbon [23]. However, the technology of biological remediation (bioremediation) has gained greater importance in recent years because it does not produce by-products and is environmentally friendly[24]. This technique uses a biological material as sorbent. A wide variety of agricultural and industrial wastes were tested as biosorbents for TCs, like macadamia nut shells [25]or rice straw [26]. From all possible biological materials, the use of biomass from microorganisms such as bacteria, fungi or microalgae have gained great interest and attractiveness as a potential candidate for use as biosorbents [27], [28], [29] and [30]. Most of these applications use dead biomass due to its advantages compared to the living biomass, for example, the dead biomass is independent of growth, is not subject to limitations of toxicity and its processes are not governed by biological constraints[31] and [32]. However, the use of living biomass can offer some advantages in some cases. Thus, the use of living biomass may be more appropriate for some applications when the toxicity of the pollutant is low or is in a concentration whose toxicity does not mean a total inhibition. In these cases, it can be very useful that the used biological material retains its activity because in this way, the ability to store large amounts of the pollutant (bioaccumulation) or to transform a pollutant in less active forms (biotransformation) is preserved, increasing the efficiency because the pollutant not only is removed by adsorption. Currently few works focused on assessing the possibilities of using living biomass for this purpose.

The main objective of this study is to investigate the kinetics, isotherms, and capacity for the removal of OTC by biomass obtained from a microalgal species. The selected microalga was Phaeodactylum tricornutum. This species is widely used in aquaculture for feeding live prey, fish and crustacean larvae. In addition, it is a microalga widely studied and reported as a model diatom. For these reasons, this species is easy to culture and its biomass is cheap. Living and dead biomass of this microalga were used and compared. 
Four kinetic models and four sorption isotherm models were used to characterize the process. In addition, the usefulness of this biomass in relation to other OTC removal procedures is discussed.

\section{EXPERIMENTAL}

\subsection{Microorganism and reagents}

The biomass used was collected from the marine microalga Phaeodactylum tricornutumBohlin cultured under appropriate conditions in the laboratory. This microalga was cultured in natural seawater with ALGAL medium at $18 \pm 2{ }^{\circ} \mathrm{C}$ under a light intensity of $3500 \mathrm{Lux}$ using cool fluorescent light with a light/dark cycle of 12:12 h. Natural sterile air was constantly bubbled at a flow rate of $10 \mathrm{~L} \mathrm{~min}^{-1}$.

Oxytetracycline dihydrate, oxalic acid, acetonitrile, methanol and $\mathrm{NaOH}$ were purchased from Sigma (St. Louis, MO, USA). Double deionized water with $18.2 \mathrm{M} \Omega \mathrm{cm}^{-1}$ of resistivity was obtained from a Milli$\mathrm{Q}^{\circledR}$ system (Millipore Co, Bedford, MA, USA). The seawater used for the experiments was natural organicfree seawater with a salinity of $35 \%$ and $\mathrm{pH}=8.2$. The natural seawater was passed through a Millipore filter of nitrocellulose (Millipore Iberica, S.A., Madrid) with a pore size of $0.22 \mu \mathrm{m}$ and through a charcoal column to remove organic substances. Finally, this seawater was sterilized at $121{ }^{\circ} \mathrm{C}$ for $20 \mathrm{~min}$.

A stock solution of OTC was freshly prepared by dissolving oxytetracycline dihydrate in methanol to obtain a final concentration of $1 \mathrm{mg} \mathrm{mL}^{-1}$. Oxalic acid was prepared in Milli-Q water to obtain a final concentration of $0.05 \mathrm{M}$ and basified to $\mathrm{pH} 2.5$ by adding $\mathrm{NaOH}$. All solvents were filtered through a Millipore filter with a pore size of $0.22 \mu \mathrm{m}$.

\subsection{Obtaining of the microalgal biomass}

Both living and dead biomass of the microalga were used in the experiments. The dead biomass was obtained by freeze-drying. A volume of the stock culture of $P$. tricornutumwas centrifuged at $4500 \mathrm{~g}$ and $4{ }^{\circ} \mathrm{C}$ for $15 \mathrm{~min}$. The pellet was resuspended in a solution of ammonium formate (1\%) to remove salts and centrifuged again. Finally, the pellet was lyophilized in a Telstar lyophilizer (Cryodos-80 model). After lyophilization, the dried biomass was stored in a desiccator to avoid moisture absorption. The living biomass was obtained from an appropriate volume of the stock culture of the microalga (at the middle of the logarithmic phase) and in order to obtain a number of cells equivalent to the amount of lyophilized biomass used in the experiments. This volume was calculated taking into account the culture cell density (obtained by counting in Neubauer camera) and the cell dry weight.

\subsection{Biosorption experiments}

The biosorption experiments were carried out in Kimax glass tubes for $11 \mathrm{~h}$, at a constant temperature of $18 \pm 2{ }^{\circ} \mathrm{C}$ and under an illumination of $3500 \mathrm{Lux}$ provided by Mazda fluorescent tubes (Osram 
L36W/765, Germany). The Kimax tubes were gently shaken to ensure homogeneity on an orbital shaker (Skyline S-3.08 M) at $200 \mathrm{rpm}$.

For the realization of the experiments, to each Kimax tube, an appropriate volume of the seawater and of the OTC stock solution were added to obtain a final concentration of $2.5,5,7.5,10,12.5$ or $15 \mathrm{mg} \mathrm{L}^{-1}$ of OTC. Then, an appropriate amount of the lyophilized biomass or an appropriate volume of the stock culture of the living microalga were placed in the tubes (this volume was previously taken into consideration to not vary the final concentration of OTC). In both cases, the biomass concentration was equivalent to $0.4 \mathrm{~g} \mathrm{~L}^{-1}$ of dry biomass. The tubes with the lyophilized biomass were vigorously agitated in a Vortex mixer to ensure a good homogenization. Two control cultures were included, one control with OTC but without biomass, and another with OTC and without biomass but in darkness. All the biosorption experiments were carried out in triplicate. Samples were collected at time 0, 0.083, 0.25, 0.5, 1, 1.5, 2, 3, 4, 5, 6, 7, 8, 9, 10 and $11 \mathrm{~h}$. The collected samples were centrifuged for $10 \mathrm{~min}$ at $14000 \mathrm{~g}$ and the supernatant was always kept in darkness and under congelation $\left(-20^{\circ} \mathrm{C}\right)$ for further analysis by High Performance Liquid Chromatography (HPLC).

\subsection{Analytical methods}

The amount of OTC remaining in the supernatants was measured by HPLC using a Hewlett-Packard 1050 equipped with an UV detector and a reverse-phase ZORBAX Eclipse XDB-C18 column $(4.6 \mathrm{~mm} \times 250 \mathrm{~mm} \times 5 \mu \mathrm{m})$. The mobile phase consisted in a mixture of oxalic acid $0.05 \mathrm{M} /$ acetonitrile $(75: 25, \mathrm{v} / \mathrm{v}) \mathrm{pH}=2.5$. Isocratic elution with a constant flow rate of $1 \mathrm{~mL} \mathrm{~min}^{-1}$ at room temperature was used. The injection volume was $20 \mu \mathrm{L}$. The detector wavelength was set at $350 \mathrm{~nm}$. The estimated Limit of Detection (LOD) was $0.05 \mathrm{mg} \mathrm{L}^{-1}$.

The amount of OTC removed per gram of the biosorbent at each sampling time $q_{t}\left(\mathrm{mg} \mathrm{g}^{-1}\right)$ was calculated as follows:

$$
q_{t}=\frac{\left(C_{c}-C_{t}\right) \times V}{m}
$$

where $C_{t}\left(\mathrm{mg} \mathrm{L}^{-1}\right)$ is the OTC concentration in the solution at time $t, \mathrm{C}_{\mathrm{c}}\left(\mathrm{mg} \mathrm{L}^{-1}\right)$ is the OTC concentration in solution at that same time in the control tubes exposed to the light but without biomass, $V(\mathrm{~L})$ is the volume used in the experiments and $m(\mathrm{~g})$ is the mass of the biosorbent.

The percentage of OTC removed from the solution was calculated as follows:

$$
R_{t}=\frac{\left(C_{0}-C_{t}\right) \times 100}{C_{0}}
$$

where $C_{0}\left(\mathrm{mg} \mathrm{L}^{-1}\right)$ is the initial OTC concentration in the solution. 


\subsection{Determination of sorption kinetics}

The kinetics of sorption describes the rate of OTC removed by the microalgal biomass. The kinetic parameters are useful for the prediction of sorption rate, which gives important information for designing and modeling the process. Sorption kinetics is commonly described with pseudo-first order and pseudo-second order kinetic models, for this reason, these models were used in the present study. However, the intraparticle diffusion model and a sigmoidal model (Chapman) were also included.

\subsubsection{Pseudo-first order kinetic model}

The pseudo-first order kinetic model [33] has been extensively used to interpret the adsorption rate of organic compounds on different adsorbents. It can be represented by the following equation:

$$
\mathrm{q}=\mathrm{q}_{\mathrm{e}}\left(1-\mathrm{e}^{-\mathrm{k}}{ }_{1}{ }^{\mathrm{t}}\right)
$$

where $q\left(\mathrm{mg} \mathrm{g}^{-1}\right)$ is the mass of OTC sorbed at time $t, k_{l}\left(\mathrm{~h}^{-1}\right)$ is the rate constant of the first-order kinetic model and $q_{e}$ is the mass of OTC sorbed at equilibrium.

\subsubsection{Pseudo-second order kinetic model}

The pseudo-second order kinetic model [34] is represented by the equation:

$$
q=\frac{q_{e}^{2} k_{2} t}{1+q_{e} k_{2} t}
$$

where $k_{2}\left(\mathrm{~g} \mathrm{mg}^{-1} \mathrm{~h}^{-1}\right)$ is the rate constant of the second-order kinetic model.

\subsubsection{Intraparticle diffusion model}

This model, proposed by Weber and Morris [35], assumes that the adsorption mechanism occurs through the diffusion of adsorbate molecules into the pores of adsorbent material. It is a functional relationship found empirically, common to the most adsorption processes, where uptake varies almost proportionally with $t^{0.5}$ rather than with the contact time $t$ :

$$
\mathrm{q}=\mathrm{k}_{\mathrm{i}} \mathrm{t} 0.5
$$

where $k_{i}\left(\mathrm{mg} \mathrm{g}^{-1} \mathrm{~h}^{-0.5}\right)$ is the intraparticle diffusion rate constant.

\subsubsection{Sigmoidal chapman model}

The Sigmoidal Chapman model was also included in this study. It is represented by the equation:

$$
q=q_{e} c(1-e-b t)
$$


where $b\left(\mathrm{~h}^{-1}\right)$ is the adsorption rate constant, and $c$ indicates the change of adsorption rate as a function of time.

\subsection{Determination of biosorption isotherms}

The Langmuir [36], Freundlich [37], Temkin [38] and Dubinin-Radushkevich [39] isotherm models were considered to study the characteristics of the dead and living biomass of $P$. tricornutum in the removal of OTC.

The Langmuir isotherm model can be represented by the following equation:

$\mathrm{q}_{\mathrm{e}}=\left(\mathrm{q}_{\max } \mathrm{K}_{\mathrm{L}} \mathrm{C}_{\mathrm{e}}\right) /\left(1+\mathrm{K}_{\mathrm{L}} \mathrm{C}_{\mathrm{e}}\right)$

where $q_{e}\left(\mathrm{mg} \mathrm{g}^{-1}\right)$ is the amount of OTC sorbed at equilibrium per unit of mass of $P$. tricornutum, $C_{e}\left(\mathrm{mg} \mathrm{L}^{-1}\right)$ is the OTC concentration in solution at equilibrium, $q_{\max }(\mathrm{mg} / \mathrm{g})$ is the maximum sorption capacity or theoretical isotherm saturation capacity, $K_{L}\left(\mathrm{~L} \mathrm{mg}^{-1}\right)$ is the constant related to the affinity for the biomaterial. According to Hall et al. [40], the essential features of the Langmuir isotherm can be expressed in terms of a dimensionless constant separation factor, $R_{L}$, which is defined by the equation:

$\mathrm{R}_{\mathrm{L}}=1 /\left(1+\mathrm{K}_{\mathrm{L}} \mathrm{C}_{0}\right)$

where $C_{0}\left(\mathrm{mg} \mathrm{L}^{-1}\right)$ is the initial OTC concentration and $K_{L}\left(\mathrm{~L} \mathrm{mg}^{-1}\right)$ is the Langmuir constant.

The Freundlich isotherm presents the following equation:

$$
q_{e}=K_{f} C_{e}^{1 / n}
$$

where $K_{F}\left(\mathrm{~L} \mathrm{mg}^{-1}\right)$ is the Freundlich constant, an indicator of the sorption capacity, and $n$ is of the intensity.

The Temkin isotherm model can be described by the equation:

$$
q_{e}=\left(\frac{R T}{b_{T}}\right) \ln \left(A_{T} C_{e}\right)
$$

where $A_{T}\left(\mathrm{~L} \mathrm{~g}^{-1}\right)$ is the Temkin isotherm equilibrium binding constant, corresponding to the maximum binding energy, $b_{T}\left(\mathrm{~J} \mathrm{~mol}^{-1}\right)$ is a constant related to the heat of sorption, $R$ is the gas constant $\left(8.314 \mathrm{~J} \mathrm{~mol}^{-1} \mathrm{~K}^{-1}\right)$ and $T$ is the absolute temperature.

The Dubinin-Radushkevich isotherm model can be represented by the equation:

$$
\mathrm{q}_{\mathrm{e}}=\mathrm{q}_{\max } \mathrm{e}-\mathrm{B}_{\mathrm{D}} \varepsilon^{2}
$$


where $B_{D}$ is related to the free energy sorption per mole of the sorbate and $\varepsilon$ is the Polanyi potential which is related to the equilibrium concentration as follows:

$$
\varepsilon=\mathrm{RT} \ln \left(1+1 / \mathrm{C}_{\mathrm{e}}\right)
$$

The apparent energy $\left(E_{D}, \mathrm{~kJ} \mathrm{~mol}^{-1}\right)$ of sorption from Dubinin-Radushkevich isotherm model can be computed using Eq. (13):

$$
E_{D}=1 / \sqrt[2]{2 B_{D}}
$$

\subsection{Statistical analysis}

Biosorption data were fitted to the kinetic and isotherm equations (Eqs. (3)-(11)) using non-linear regression analysis. All data represent the mean of three independent experiments and the statistical analysis and plots were performed using SigmaPlot for Windows version 12.5 (Systat Software, Inc.).

In order to evaluate the goodness of the kinetic and isotherm models to the experimental data, different error functions were used (Table 1). If data derived from a model are similar to the experimental data, the value of the error functions will be low; otherwise, if they differ, the value will be high. Only in the case of $r^{2}$, a higher value indicates the best fit of the model. In all cases, the error function initially selected to minimize the non-linear regression was SSE. With the parameters obtained were calculated the values for all the other error functions.

\begin{tabular}{|c|c|}
\hline Name & Equations \\
\hline Normalized standard deviation (\%) & $\Delta q=100(1 N-1) \sum i=1 n(q e, \exp -q e, c a l c q e, \exp ) 2$ \\
\hline Sum of the squares of the errors & $\mathrm{SSE}=\sum \mathrm{i}=\ln (\mathrm{qe}, \exp -\mathrm{qe}, \mathrm{calc}) 2$ \\
\hline Average relative error & $\mathrm{ARE}=100 \mathrm{~N} \sum \mathrm{i}=1 \mathrm{n} \mid \mathrm{qe}, \exp -\mathrm{qe}$, calcqe, $\exp \mid$ \\
\hline Hybrid functional error & HYBRID $=100(N-P) \sum i=1 n(q e, \exp -q e, c a l c) 2 q e, \exp$ \\
\hline Sum of absolute error & $\mathrm{EABS}=\sum \mathrm{i}=1 \mathrm{n}|\mathrm{qe}, \exp -\mathrm{qe}, \mathrm{calc}|$ \\
\hline $\begin{array}{l}\text { Marquardt's percent standard } \\
\text { deviation }\end{array}$ & MPSD $=100(1 \mathrm{~N}-\mathrm{P}) \sum \mathrm{i}=\ln (\mathrm{qe}, \exp -\mathrm{qe}$, calcqe, exp $) 2$ \\
\hline Nonlinear chi-square test & $\chi^{2}=\sum \mathrm{i}=\ln (\mathrm{qe}, \exp -\mathrm{qe}$, calc $) 2 \mathrm{qe}$, calc \\
\hline Residual root mean square error & $\mathrm{RMSE}=(1 \mathrm{~N}-2) \sum \mathrm{i}=\ln (\mathrm{qe}, \exp -\mathrm{qe}$, calc $) 2$ \\
\hline Coefficient of determination & 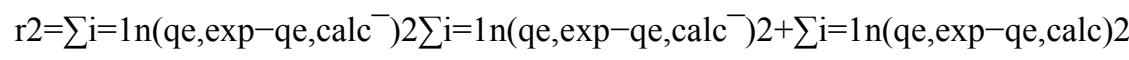 \\
\hline \multicolumn{2}{|c|}{$q_{e, \exp }\left(\mathrm{mg} \mathrm{g}^{-1}\right):$ value obtained from the experiment. } \\
\hline \multicolumn{2}{|c|}{$q e_{, \text {calc }}\left(\mathrm{mg} \mathrm{g}^{-1}\right)$ :calculated value for corresponding $q e_{, \exp }$} \\
\hline \multicolumn{2}{|c|}{$N$ : number of observations in the experiment. } \\
\hline$P:$ number of parameters in the respec & ive model. \\
\hline
\end{tabular}

Table 1. Equations of the error functions used in this study. 


\section{RESULTS AND DISCUSSION}

\subsection{Photodegradation of OTC}

Since OTC is sensitive to the photodegradation and as the culture of microalgae requires light, it is logical to think that a part of OTC is being eliminated by this mechanism. For this reason, to assess the amount of lost OTC not due to the action of the biomass, control experiments without biomass but under the same exposure conditions, and control experiments in darkness were performed. The Kimax tubes kept in dark did not show a significant reduction in the OTC concentration throughout the experiment, remaining this compound stable. However, under lighting conditions without biomass, the residual concentration of OTC decreased exponentially throughout the time of exposure (Fig. 1a). Thus, during the experiments (11 h), around of a $21 \%$ of the initial OTC concentrations were degraded due to abiotic conditions (photolytic degradation). However, the presence of biomass increased considerably this percentage (Fig. 1b,c). In fact, the residual OTC concentration was lower in the tubes that were both irradiated and inoculated than in the tubes that were only irradiated. The greatest decrease occurred when living biomass was used, with a removal capacity of $97 \%$ in the tubes with the lower OTC concentration assayed. This efficiency was lower with dead biomass because the percentage of elimination was only $45 \%$ in this same concentration. Although this percentage remained always superior in comparison with the abiotic removal. De Godos et al. [41] found that tetracycline removal was most likely caused by photodegradation than by the presence of biomass during wastewater treatment in high-rate algal ponds composed mainly of biomass of the microalga $C$. vulgaris. Although in this case the antibiotic was tetracycline, this biomass appears to be less efficient than the case of $P$. tricornutum and these authors use a supplement of ultraviolet light.
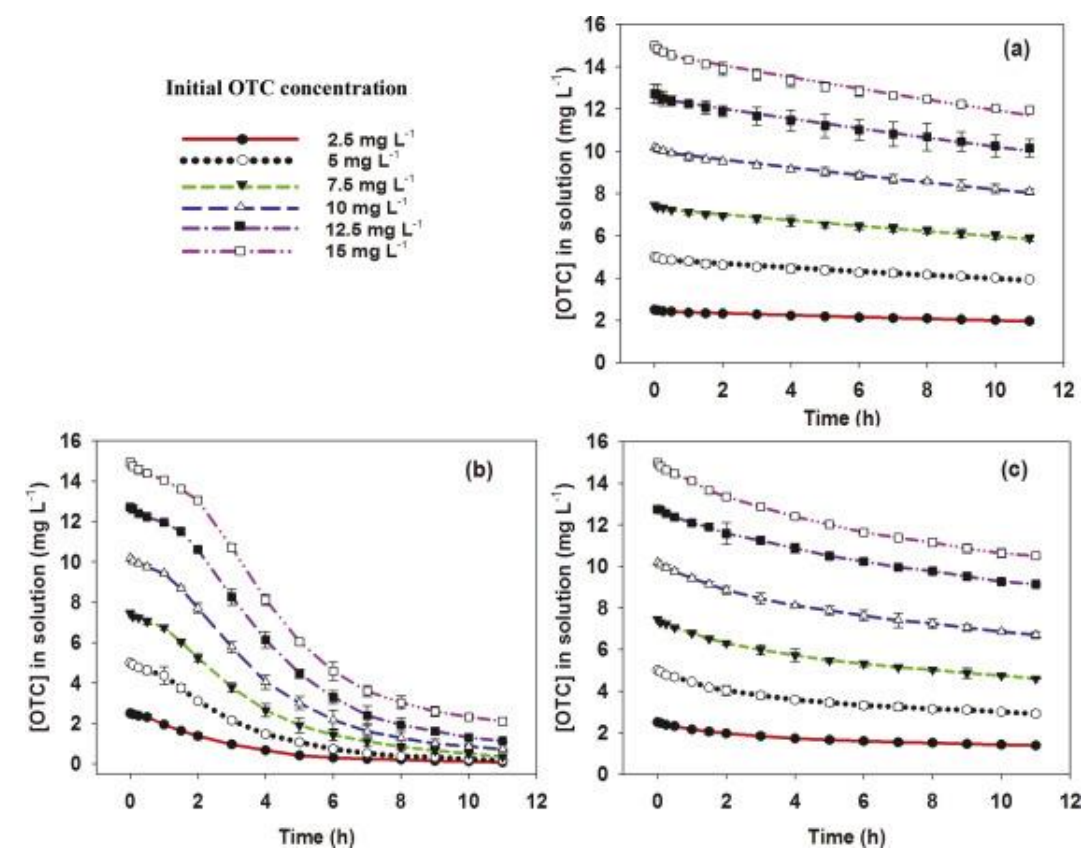

Fig. 1. Evolution of the OTC concentration in the solution throughout the time of exposure, (a) in tubes exposed only to the light without biomass, (b) with light and living biomass, (c) with light and dead biomass. 


\subsection{Effect of contact time}

As shown in Fig. 2, removal of OTC by the biomass increased with the increase in the contact time. This figure represents the total amount of OTC eliminated (abiotic + biomass) per unit of volume of solution (Figs. 2a,b) and the amount eliminated only by the biomass (Figs. 2c,d). In the experiments exposed to the light and with living biomass (Fig. 2a), a pseudo-equilibrium was attained in $5 \mathrm{~h}$ in the lower OTC concentration, reflecting a rapid elimination. However, the time to reach this pseudo-equilibrium was superior as the OTC concentration increased. At the highest concentration, the pseudo-equilibrium was achieved after $10 \mathrm{~h}$.
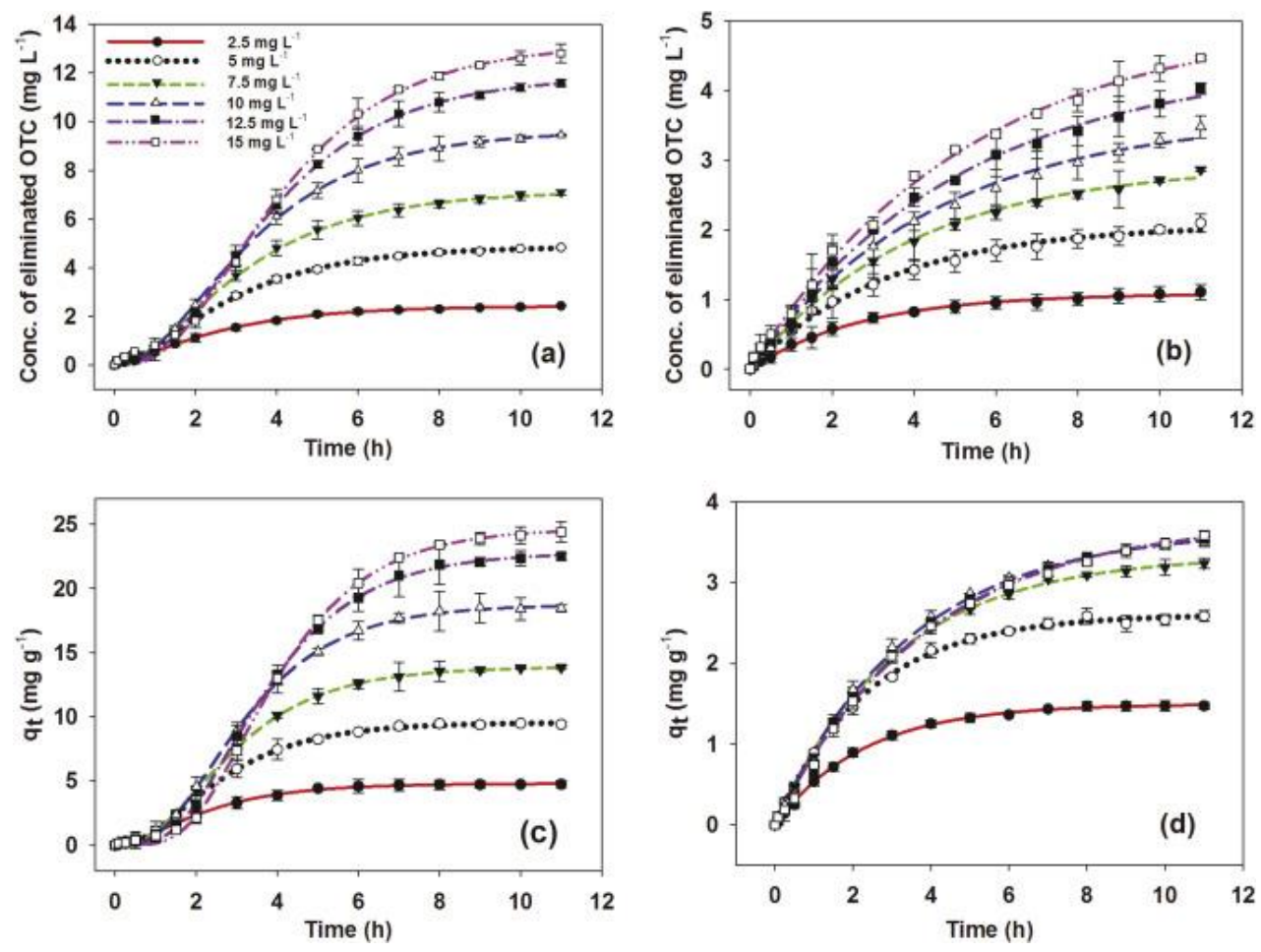

Fig. 2. Effect of contact time on the total amount of OTC eliminated per unit of volume, (a) abiotic + living biomass, (b) abiotic + dead biomass. Amount of OTC eliminated per unit of biomass considering only the living (c) and dead (d) biomass.

In the case of dead biomass (Fig. 2b), a pseudo-equilibrium was reached after $4 \mathrm{~h}$ in the lowest OTC concentration. After a rapid elimination phase, a true equilibrium was not observed. As in the previous case, this was because the photodegradation continued throughout the time of the experiment. However, when the amount of OTC eliminated only by the biomass is considered (without taking into account the eliminated abiotically), an equilibrium was reached (Figs. 2c,d). The times to achieve these equilibriums were the same as to achieve the pseudo-equilibriums. These obtained times to achieve the equilibria were lower than in other literature data. The adsorption equilibrium time for tetracycline antibiotics required about $17 \mathrm{~h}$ with petroleum coke derived activated carbons [42] or about $12 \mathrm{~h}$ with activated carbon fiber [43]. 
Hence, observing Fig. 2, a contact time of $11 \mathrm{~h}$ was suitable for the experiments, ensuring the achievement of equilibrium conditions in relation to the biomass.

\subsection{Effect of the initial OTC concentration}

The total amount of OTC eliminated per unit of biomass increased with the initial OTC concentration in the solution (Fig. 2). When the removed amount is considered without taking into account the abiotic degradation, removal with dead biomass (Fig. 2d) reached values of saturation when the initial OTC concentration was $10 \mathrm{mg} \mathrm{L}^{-1}$. In the case of living biomass, saturation only began to be observed at the highest initial OTC concentration. This results in that, when the removed amount is expressed as percentage in relation to the initial amount, the removal capacity decreased with the increase of the initial OTC concentration. This occurred for both biomasses. The percentage of total OTC removed from the solution was $97 \%$ when the initial OTC concentration was $2.5 \mathrm{mg} \mathrm{L}^{-1}$ and living biomass was used. With dead biomass the percentage of total OTC removed was only $44.8 \%$. When the initial OTC concentration was $15 \mathrm{mg} \mathrm{L}^{-1}$, the percentage removed was only $85.8 \%$ and $29.9 \%$ with living and dead biomass, respectively. Algal-mediated biodegradation contributed to significantly increase the amount of OTC removed.

\subsection{Removal kinetics}

In order to evaluate the removal kinetics of OTC onto living and dead microalgal biomass, different kinetic models were fitted to experimental data. In addition, since the photodegradation will always accompany the process of bioremediation with a live microalgal culture, it is important to assess both processes together (biomass + abiotic), for which the same kinetic models were also used. The kinetic parameters obtained by nonlinear regression are listed in Table 2 and Table 3 and the measure of the goodness of fit with the statistical error deviation functions are listed in Table 4, Table 5, Table 6 and Table 7. 
Table 2. Kinetic parameters for the removal of OTC by living and dead biomass of the microalga P. tricornutum. Data are expressed by unit of mass.

\begin{tabular}{|c|c|c|c|c|c|c|c|c|c|}
\hline \multirow{3}{*}{$\begin{array}{l}\text { Initial OTC } \\
\text { concentration } \\
\left(\mathrm{mg} \mathrm{L}^{-1}\right)\end{array}$} & \multirow{3}{*}{$\begin{array}{l}\text { Type of } \\
\text { Biomass }\end{array}$} & \multicolumn{8}{|c|}{ Kinetic Model } \\
\hline & & \multicolumn{2}{|c|}{ Pseudo-first order } & \multicolumn{2}{|c|}{ Pseudo-second order } & \multirow{2}{*}{$\begin{array}{l}\text { Intraparticle diffusion } \\
k_{i}\left(m g g^{-1} h^{-0.5}\right)\end{array}$} & \multicolumn{3}{|c|}{ Sigmoidal (Chapman) } \\
\hline & & $q_{e}\left(m g g^{-1}\right)$ & $k_{l}\left(h^{-1}\right)$ & $q_{e}\left(m g g^{-1}\right)$ & $k_{2}\left(g m g^{-I} h^{-1}\right)$ & & $q_{e}\left(m g g^{-1}\right)$ & $b\left(h^{-1}\right)$ & $c$ \\
\hline \multirow[t]{2}{*}{2.5} & Living & 5.11 & 0.32 & 6.86 & 0.04 & 1.63 & 4.78 & 0.60 & 1.96 \\
\hline & Dead & 1.50 & 0.44 & 1.86 & 0.24 & 0.52 & 1.48 & 0.48 & 1.09 \\
\hline \multirow[t]{2}{*}{5} & Living & 10.78 & 0.24 & 15.46 & 0.01 & 3.15 & 9.54 & 0.59 & 2.60 \\
\hline & Dead & 2.61 & 0.42 & 3.25 & 0.13 & 0.90 & 2.60 & 0.43 & 1.01 \\
\hline \multirow[t]{2}{*}{7.5} & Living & 16.86 & 0.19 & 25.66 & 0.005 & 4.45 & 13.90 & 0.58 & 3.15 \\
\hline & Dead & 3.34 & 0.33 & 4.38 & 0.07 & 1.08 & 3.30 & 0.34 & 1.08 \\
\hline \multirow[t]{2}{*}{10} & Living & 24.60 & 0.16 & 39.43 & 0.002 & 5.84 & 18.74 & 0.59 & 3.90 \\
\hline & Dead & 3.67 & 0.29 & 4.96 & 0.05 & 1.15 & 3.53 & 0.38 & 1.24 \\
\hline \multirow[t]{2}{*}{12.5} & Living & 36.90 & 0.10 & 64.68 & 0.0009 & 6.76 & 22.80 & 0.58 & 5.10 \\
\hline & Dead & 3.77 & 0.26 & 5.20 & 0.04 & 1.14 & 3.62 & 0.33 & 1.21 \\
\hline \multirow[t]{2}{*}{15} & Living & 48.33 & 0.07 & 89.27 & 0.0004 & 7.14 & 24.69 & 0.59 & 6.50 \\
\hline & Dead & 3.80 & 0.25 & 5.26 & 0.04 & 1.13 & 3.67 & 0.30 & 1.14 \\
\hline
\end{tabular}

Table 3. Kinetic parameters for the total removal (photolysis + living or dead biomass) of OTC. Data are expressed by unit of volume of solution.

\begin{tabular}{|c|c|c|c|c|c|c|c|c|c|}
\hline \multirow{3}{*}{$\begin{array}{l}\text { Initial OTC } \\
\text { concentration } \\
\left(\mathrm{mg} \mathrm{L}^{-1}\right)\end{array}$} & \multirow{3}{*}{$\begin{array}{l}\text { Type o } \\
\text { Biomass }\end{array}$} & \multicolumn{8}{|c|}{ Kinetic Model } \\
\hline & & \multicolumn{2}{|c|}{ Pseudo-first order } & \multicolumn{2}{|c|}{ Pseudo-second order } & \multirow{2}{*}{$\begin{array}{l}\text { Intraparticle diffusion } \\
k_{i}\left(m g L^{-1} h^{-0.5}\right)\end{array}$} & \multicolumn{3}{|c|}{ Sigmoidal (Chapman) } \\
\hline & & $q_{e}\left(m g L^{-1}\right)$ & $k_{l}\left(h^{-1}\right)$ & $q_{e}\left(m g L^{-1}\right)$ & $k_{2}\left(L m g^{-1} h^{-1}\right)$ & & $q_{e}\left(m g L^{-1}\right)$ & $b\left(h^{-1}\right)$ & $c$ \\
\hline \multirow[t]{2}{*}{2.5} & Living & 2.56 & 0.29 & 3.47 & 0.07 & 0.80 & 2.42 & 0.45 & 1.48 \\
\hline & Dead & 1.09 & 0.36 & 1.39 & 0.25 & 0.36 & 1.11 & 0.31 & 0.89 \\
\hline \multirow[t]{2}{*}{5} & Living & 5.42 & 0.23 & 7.78 & 0.02 & 1.56 & 4.86 & 0.45 & 1.85 \\
\hline & Dead & 2.07 & 0.30 & 2.73 & 0.10 & 0.66 & 2.25 & 0.20 & 0.77 \\
\hline \multirow[t]{2}{*}{7.5} & Living & 8.54 & 0.18 & 12.98 & 0.01 & 2.20 & 7.14 & 0.43 & 2.12 \\
\hline & Dead & 2.93 & 0.25 & 4.01 & 0.05 & 0.88 & 3.06 & 0.21 & 0.89 \\
\hline \multirow[t]{2}{*}{10} & Living & 12.42 & 0.15 & 19.77 & 0.005 & 2.90 & 9.62 & 0.44 & 2.53 \\
\hline & Dead & 3.64 & 0.22 & 5.08 & 0.04 & 1.03 & 3.99 & 0.16 & 0.83 \\
\hline \multirow[t]{2}{*}{12.5} & Living & 18.20 & 0.10 & 31.23 & 0.002 & 3.42 & 11.88 & 0.44 & 3.09 \\
\hline & Dead & 4.44 & 0.20 & 6.42 & 0.02 & 1.19 & 4.54 & 0.18 & 0.96 \\
\hline \multirow[t]{2}{*}{15} & Living & 22.89 & 0.08 & 40.81 & 0.001 & 3.72 & 13.20 & 0.45 & 3.57 \\
\hline & Dead & 5.07 & 0.19 & 7.39 & 0.01 & 1.34 & 5.20 & 0.17 & 0.95 \\
\hline
\end{tabular}


Table 4. Values of the error functions obtained for the kinetic models using living biomass.

\begin{tabular}{|c|c|c|c|c|c|c|c|c|c|c|}
\hline \multirow{2}{*}{$\begin{array}{l}\text { Initial OTC } \\
\text { concentration } \\
\left(m g L^{-1}\right)\end{array}$} & \multirow[t]{2}{*}{ Type of Equation } & \multicolumn{9}{|c|}{ Error Function } \\
\hline & & $\Delta q_{t}(\%)$ & SSE & $A R E$ & HYBRID & $E A B S$ & $M P S D$ & $\chi^{2}$ & $R M S E$ & $r^{2}$ \\
\hline \multirow[t]{4}{*}{2.5} & Pseudo-First Order & 92.18 & 0.83 & 45.16 & 14.85 & 2.98 & 0.96 & 0.76 & 0.25 & 0.986 \\
\hline & Pseudo-Second Order & 106.73 & 1.43 & 53.21 & 20.03 & 4.05 & 1.11 & 1.01 & 0.33 & 0.976 \\
\hline & Intraparticle Diffusion & 302.95 & 4.20 & 132.83 & 84.22 & 7.05 & 3.03 & 2.51 & 0.57 & 0.929 \\
\hline & Sigmoidal (Chapman) & 22.59 & 0.039 & 9.91 & 0.59 & 0.65 & 0.23 & 0.13 & 0.05 & 0.999 \\
\hline \multirow[t]{4}{*}{5} & Pseudo-First Order & 59.44 & 5.48 & 34.76 & 27.05 & 7.85 & 0.62 & 1.89 & 0.65 & 0.977 \\
\hline & Pseudo-Second Order & 65.00 & 7.50 & 38.73 & 32.09 & 9.42 & 0.67 & 2.25 & 0.76 & 0.969 \\
\hline & Intraparticle Diffusion & 213.88 & 18.89 & 110.91 & 150.31 & 15.05 & 2.14 & 5.93 & 1.21 & 0.923 \\
\hline & Sigmoidal (Chapman) & 36.46 & 0.24 & 16.73 & 4.01 & 1.53 & 1.24 & 6.41 & 0.13 & 0.999 \\
\hline \multirow[t]{4}{*}{7.5} & Pseudo-First Order & 110 & 15.31 & 61.38 & 78.28 & 12.89 & 1.14 & 4.01 & 1.09 & 0.971 \\
\hline & Pseudo-Second Order & 113.44 & 18.54 & 63.99 & 83.08 & 14.58 & 1.18 & 4.35 & 1.19 & 0.965 \\
\hline & Intraparticle Diffusion & 365.85 & 48.34 & 189.96 & 429.46 & 22.73 & 3.66 & 11.10 & 1.93 & 0.908 \\
\hline & Sigmoidal (Chapman) & 39.39 & 0.17 & 17.75 & 4.29 & 1.10 & 4.49 & 23.15 & 0.01 & 0.999 \\
\hline \multirow[t]{4}{*}{10} & Pseudo-First Order & 165.52 & 36.68 & 88.57 & 176.21 & 19.89 & 1.72 & 6.99 & 1.68 & 0.962 \\
\hline & Pseudo-Second Order & 166.09 & 41.46 & 89.29 & 177.62 & 21.27 & 1.72 & 7.29 & 1.79 & 0.957 \\
\hline & Intraparticle Diffusion & 485.82 & 108.3 & 260.53 & 901.23 & 34.13 & 4.86 & 18.05 & 2.89 & 0.888 \\
\hline & Sigmoidal (Chapman) & 0.42 & 0.316 & 19.05 & 5.41 & 1.86 & 12.82 & 281.96 & 0.02 & 0.999 \\
\hline \multirow[t]{4}{*}{12.5} & Pseudo-First Order & 191.58 & 65.08 & 112.63 & 274.62 & 26.51 & 1.99 & 10.32 & 2.24 & 0.954 \\
\hline & Pseudo-Second Order & 191.89 & 68.64 & 113.10 & 275.40 & 27.53 & 1.99 & 10.47 & 2.29 & 0.952 \\
\hline & Intraparticle Diffusion & 653.95 & 200 & 367.72 & 1580.28 & 45.28 & 6.54 & 26.81 & 3.92 & 0.859 \\
\hline & Sigmoidal (Chapman) & 47.53 & 0.49 & 23.70 & 7.52 & 2.20 & 6.14 & 5267.35 & 0.19 & 0.999 \\
\hline \multirow[t]{4}{*}{15} & Pseudo-First Order & 207.84 & 86.58 & 127 & 339.14 & 30.47 & 2.16 & 12.45 & 2.58 & 0.949 \\
\hline & Pseudo-Second Order & 176.84 & 115.87 & 110.28 & 263.14 & 35.03 & 1.84 & 13.33 & 2.99 & 0.948 \\
\hline & Intraparticle Diffusion & 764.39 & 269.07 & 434.76 & 2057.34 & 54.28 & 7.64 & 32.35 & 4.54 & 0.842 \\
\hline & Sigmoidal (Chapman) & 51.86 & 0.79 & 28.31 & 9.45 & 2.47 & 0.56 & 286888 & 0.25 & 0.999 \\
\hline
\end{tabular}


Table 5. Values of the error functions obtained for the kinetic models using dead biomass.

\begin{tabular}{|c|c|c|c|c|c|c|c|c|c|c|}
\hline \multirow{2}{*}{$\begin{array}{l}\text { Initial OTC } \\
\text { Concentration } \\
\left(m g L^{-1}\right)\end{array}$} & \multirow[t]{2}{*}{ Type of Equation } & \multicolumn{9}{|c|}{ Error Function } \\
\hline & & $\Delta q_{t}(\%)$ & $S S E$ & $A R E$ & HYBRID & $E A B S$ & $M P S D$ & $\chi^{2}$ & $R M S E$ & $r^{2}$ \\
\hline \multirow[t]{4}{*}{2.5} & Pseudo-First Order & 13.09 & 0.004 & 5.39 & 0.14 & 0.20 & 0.14 & 0.01 & 0.02 & 0.999 \\
\hline & Pseudo-Second Order & 24.24 & 0.03 & 11.84 & 0.61 & 0.57 & 0.25 & 0.06 & 0.05 & 0.994 \\
\hline & Intraparticle Diffusion & 85.49 & 0.29 & 36.91 & 4.96 & 1.84 & 0.85 & 0.39 & 0.15 & 0.939 \\
\hline & Sigmoidal (Chapman) & 5.94 & 0.003 & 3.01 & 0.05 & 0.16 & 0.06 & 0.01 & 0.02 & 0.999 \\
\hline \multirow[t]{4}{*}{5} & Pseudo-First Order & 3.15 & 0.02 & 2.31 & 0.08 & 0.40 & 0.03 & 0.01 & 0.04 & 0.999 \\
\hline & Pseudo-Second Order & 8.86 & 0.08 & 6.02 & 0.46 & 0.94 & 0.09 & 0.06 & 0.08 & 0.995 \\
\hline & Intraparticle Diffusion & 51.89 & 0.78 & 26.20 & 5.52 & 3.04 & 0.52 & 0.55 & 0.25 & 0.946 \\
\hline & Sigmoidal (Chapman) & 3.60 & 0.02 & 2.51 & 0.09 & 0.40 & 0.04 & 0.01 & 0.04 & 0.998 \\
\hline \multirow[t]{4}{*}{7.5} & Pseudo-First Order & 5.21 & 0.02 & 3.06 & 0.13 & 0.35 & 0.05 & 0.02 & 0.03 & 0.999 \\
\hline & Pseudo-Second Order & 10.70 & 0.09 & 6.56 & 0.63 & 0.99 & 0.11 & 0.07 & 0.08 & 0.996 \\
\hline & Intraparticle Diffusion & 70.61 & 0.76 & 34.47 & 9.23 & 3.08 & 0.71 & 0.67 & 0.24 & 0.967 \\
\hline & Sigmoidal (Chapman) & 7.16 & 0.009 & 2.86 & 0.11 & 0.29 & 0.08 & 0.02 & 0.03 & 0.999 \\
\hline \multirow[t]{4}{*}{10} & Pseudo-First Order & 10.51 & 0.07 & 5.95 & 0.65 & 0.77 & 0.11 & 0.07 & 0.07 & 0.998 \\
\hline & Pseudo-Second Order & 15.18 & 0.18 & 8.99 & 1.41 & 1.37 & 0.16 & 0.15 & 0.12 & 0.994 \\
\hline & Intraparticle Diffusion & 82.48 & 0.99 & 41.91 & 13.56 & 3.47 & 0.82 & 0.91 & 0.28 & 0.963 \\
\hline & Sigmoidal (Chapman) & 15.64 & 0.02 & 6.79 & 0.45 & 0.44 & 0.17 & 0.09 & 0.04 & 0.998 \\
\hline \multirow[t]{4}{*}{12.5} & Pseudo-First Order & 16.35 & 0.07 & 8.46 & 1.09 & 0.68 & 0.17 & 0.10 & 0.08 & 0.997 \\
\hline & Pseudo-Second Order & 21.23 & 0.15 & 10.62 & 1.87 & 1.12 & 0.22 & 0.17 & 0.11 & 0.995 \\
\hline & Intraparticle Diffusion & 97.93 & 0.94 & 49.32 & 18.12 & 3.13 & 0.98 & 1.02 & 0.27 & 0.966 \\
\hline & Sigmoidal (Chapman) & 15.07 & 0.04 & 7.31 & 0.55 & 0.60 & 0.16 & 0.08 & 0.05 & 0.998 \\
\hline \multirow[t]{4}{*}{15} & Pseudo-First Order & 13.62 & 0.04 & 7.02 & 0.64 & 0.58 & 0.14 & 0.07 & 0.06 & 0.999 \\
\hline & Pseudo-Second Order & 18.13 & 0.09 & 9.09 & 1.22 & 0.92 & 0.19 & 0.12 & 0.08 & 0.997 \\
\hline & Intraparticle Diffusion & 96.53 & 0.82 & 47.96 & 16.94 & 2.93 & 0.97 & 0.94 & 0.25 & 0.970 \\
\hline & Sigmoidal (Chapman) & 12.48 & 0.02 & 5.58 & 0.33 & 0.52 & 0.13 & 0.05 & 0.04 & 0.999 \\
\hline
\end{tabular}


Table 6. Values of the error functions obtained for the kinetic models using living biomass and taking into account the photolysis.

\begin{tabular}{|c|c|c|c|c|c|c|c|c|c|c|}
\hline \multirow{2}{*}{$\begin{array}{l}\text { Initial OTC } \\
\text { Concentration } \\
\left(m g L^{-1}\right)\end{array}$} & \multirow[t]{2}{*}{ Type of Equation } & \multicolumn{9}{|c|}{ Error Function } \\
\hline & & $\Delta q_{t}(\%)$ & $S S E$ & $A R E$ & HYBRID & $E A B S$ & $M P S D$ & $\chi^{2}$ & $R M S E$ & $r^{2}$ \\
\hline \multirow[t]{4}{*}{2.5} & Pseudo-First Order & 36.46 & 0.08 & 17.51 & 2.26 & 0.89 & 0.38 & 0.16 & 0.08 & 0.994 \\
\hline & Pseudo-Second Order & 44.64 & 0.16 & 22.81 & 3.46 & 1.35 & 0.46 & 0.25 & 0.11 & 0.988 \\
\hline & Intraparticle Diffusion & 146.57 & 0.67 & 70.20 & 19.99 & 2.76 & 1.47 & 0.90 & 0.71 & 0.951 \\
\hline & Sigmoidal (Chapman) & 19.23 & 0.01 & 8.43 & 0.36 & 0.32 & 0.21 & 0.06 & 0.02 & 0.999 \\
\hline \multirow[t]{4}{*}{5} & Pseudo-First Order & 29.32 & 0.66 & 16.99 & 5.43 & 2.59 & 0.30 & 0.46 & 0.22 & 0.988 \\
\hline & Pseudo-Second Order & 33.47 & 0.98 & 20.40 & 7.00 & 3.30 & 0.35 & 0.59 & 0.27 & 0.983 \\
\hline & Intraparticle Diffusion & 144.12 & 3.26 & 74.81 & 44.19 & 6.07 & 1.44 & 2.22 & 1.43 & 0.943 \\
\hline & Sigmoidal (Chapman) & 31.02 & 0.07 & 14.46 & 1.97 & 0.80 & 0.34 & 0.92 & 0.07 & 0.999 \\
\hline \multirow[t]{4}{*}{7.5} & Pseudo-First Order & 44.42 & 1.86 & 25.99 & 12.72 & 4.38 & 0.46 & 0.99 & 0.38 & 0.985 \\
\hline & Pseudo-Second Order & 46.92 & 2.37 & 27.72 & 14.36 & 5.12 & 0.49 & 1.12 & 0.43 & 0.981 \\
\hline & Intraparticle Diffusion & 165.80 & 8.54 & 92.03 & 95.66 & 9.31 & 1.66 & 4.09 & 2.13 & 0.931 \\
\hline & Sigmoidal (Chapman) & 34.43 & 0.12 & 15.70 & 2.98 & 1.13 & 0.37 & 4.96 & 0.09 & 0.999 \\
\hline \multirow[t]{4}{*}{10} & Pseudo-First Order & 65.04 & 4.71 & 36.75 & 27.48 & 7.07 & 0.67 & 1.85 & 0.60 & 0.979 \\
\hline & Pseudo-Second Order & 66.51 & 5.52 & 38.02 & 28.89 & 7.73 & 0.69 & 1.98 & 0.65 & 0.976 \\
\hline & Intraparticle Diffusion & 254.65 & 19.79 & 140.57 & 208.41 & 14.38 & 2.55 & 6.96 & 2.90 & 0.913 \\
\hline & Sigmoidal (Chapman) & 37.70 & 0.11 & 16.73 & 3.36 & 0.92 & 0.41 & 9.33 & 0.09 & 0.999 \\
\hline \multirow[t]{4}{*}{12.5} & Pseudo-First Order & 65.51 & 9.11 & 39.43 & 41.37 & 9.77 & 0.68 & 2.74 & 0.84 & 0.974 \\
\hline & Pseudo-Second Order & 67.17 & 9.91 & 40.49 & 43.47 & 10.31 & 0.69 & 2.86 & 0.87 & 0.972 \\
\hline & Intraparticle Diffusion & 249.87 & 38 & 149.54 & 299.63 & 20.08 & 2.49 & 10.2 & 3.64 & 0.890 \\
\hline & Sigmoidal (Chapman) & 44.01 & 0.33 & 21.52 & 6.92 & 1.49 & 0.48 & 94.2 & 0.16 & 0.999 \\
\hline \multirow[t]{4}{*}{15} & Pseudo-First Order & 60.09 & 12.93 & 37.34 & 46.55 & 11.56 & 0.62 & 3.23 & 0.99 & 0.969 \\
\hline & Pseudo-Second Order & 62.72 & 14.01 & 38.75 & 50.39 & 11.91 & 0.65 & 3.39 & 1.04 & 0.968 \\
\hline & Intraparticle Diffusion & 244.45 & 52.58 & 151.83 & 339.95 & 24.17 & 2.44 & 12.3 & 4.08 & 0.876 \\
\hline & Sigmoidal (Chapman) & 47.86 & 0.79 & 25.85 & 10.97 & 2.63 & 0.52 & 386 & 0.25 & 0.998 \\
\hline
\end{tabular}


Table 7. Values of the error functions obtained for the kinetic models using dead biomass and taking into account the photolysis.

\begin{tabular}{|c|c|c|c|c|c|c|c|c|c|c|}
\hline \multirow{2}{*}{$\begin{array}{l}\text { Initial OTC } \\
\text { Concentration } \\
\left(m g L^{-1}\right)\end{array}$} & \multirow[t]{2}{*}{ Type of Equation } & \multicolumn{9}{|c|}{ Error Function } \\
\hline & & $\Delta q_{t}(\%)$ & SSE & $A R E$ & HYBRID & $E A B S$ & $M P S D$ & $\chi^{2}$ & RMSE & $r^{2}$ \\
\hline \multirow[t]{4}{*}{2.5} & Pseudo-First Order & 8.26 & 0.006 & 5.02 & 0.09 & 0.26 & 0.08 & 0.01 & 0.02 & 0.998 \\
\hline & Pseudo-Second Order & 6.36 & 0.004 & 3.42 & 0.09 & 0.18 & 0.07 & 0.01 & 0.02 & 0.998 \\
\hline & Intraparticle Diffusion & 45.39 & 0.07 & 22.58 & 1.72 & 0.88 & 0.45 & 0.16 & 0.07 & 0.971 \\
\hline & Sigmoidal (Chapman) & 5.09 & 0.005 & 2.86 & 0.08 & 0.20 & 0.06 & 0.01 & 0.02 & 0.998 \\
\hline \multirow[t]{4}{*}{5} & Pseudo-First Order & 12.87 & 0.03 & 7.49 & 0.49 & 0.65 & 0.13 & 0.09 & 0.06 & 0.995 \\
\hline & Pseudo-Second Order & 7.98 & 0.01 & 3.94 & 0.19 & 0.32 & 0.08 & 0.03 & 0.03 & 0.998 \\
\hline & Intraparticle Diffusion & 50.27 & 0.10 & 21.37 & 2.55 & 1.13 & 0.50 & 0.19 & 0.09 & 0.987 \\
\hline & Sigmoidal (Chapman) & 11.48 & 0.01 & 5.57 & 0.21 & 0.37 & 0.12 & 0.02 & 0.03 & 0.998 \\
\hline \multirow[t]{4}{*}{7.5} & Pseudo-First Order & 17.49 & 0.06 & 8.81 & 0.77 & 0.81 & 0.18 & 0.18 & 0.07 & 0.996 \\
\hline & Pseudo-Second Order & 17.17 & 0.04 & 8.05 & 0.76 & 0.59 & 0.18 & 0.14 & 0.06 & 0.997 \\
\hline & Intraparticle Diffusion & 46.99 & 0.29 & 24.60 & 5.91 & 1.63 & 0.47 & 0.44 & 0.15 & 0.981 \\
\hline & Sigmoidal (Chapman) & 15.67 & 0.05 & 8.14 & 0.79 & 0.68 & 0.17 & 0.11 & 0.06 & 0.997 \\
\hline \multirow[t]{4}{*}{10} & Pseudo-First Order & 12.04 & 0.13 & 7.46 & 0.75 & 1.08 & 0.12 & 0.11 & 0.09 & 0.994 \\
\hline & Pseudo-Second Order & 12.51 & 0.08 & 7.07 & 0.68 & 0.86 & 0.13 & 0.08 & 0.08 & 0.997 \\
\hline & Intraparticle Diffusion & 78.81 & 0.44 & 37.28 & 11.53 & 1.69 & 0.79 & 0.67 & 0.18 & 0.981 \\
\hline & Sigmoidal (Chapman) & 16.03 & 0.09 & 8.71 & 1.15 & 0.94 & 0.17 & 0.11 & 0.09 & 0.996 \\
\hline \multirow[t]{4}{*}{12.5} & Pseudo-First Order & 15.94 & 0.08 & 7.76 & 0.74 & 0.89 & 0.17 & 0.14 & 0.08 & 0.998 \\
\hline & Pseudo-Second Order & 15.26 & 0.07 & 7.77 & 0.78 & 0.83 & 0.16 & 0.12 & 0.07 & 0.998 \\
\hline & Intraparticle Diffusion & 61.56 & 0.82 & 34.07 & 12.32 & 2.69 & 0.62 & 0.88 & 0.25 & 0.974 \\
\hline & Sigmoidal (Chapman) & 14.46 & 0.07 & 7.42 & 0.76 & 0.88 & 0.16 & 0.11 & 0.08 & 0.998 \\
\hline \multirow[t]{4}{*}{15} & Pseudo-First Order & 16.31 & 0.08 & 8.29 & 0.78 & 0.97 & 0.17 & 0.16 & 0.08 & 0.998 \\
\hline & Pseudo-Second Order & 14.90 & 0.08 & 7.55 & 0.73 & 0.87 & 0.15 & 0.13 & 0.08 & 0.998 \\
\hline & Intraparticle Diffusion & 56.09 & 1.04 & 32.23 & 11.99 & 3.29 & 0.56 & 0.93 & 0.28 & 0.974 \\
\hline & Sigmoidal (Chapman) & 13.99 & 0.07 & 7.25 & 0.69 & 0.90 & 0.15 & 0.11 & 0.08 & 0.998 \\
\hline
\end{tabular}

As shown in Table 4 and Table 5, the removal of OTC considering only the biomasses (without photodegradation) showed different kinetic models. The removal with living biomass followed a sigmoidal kinetics, since this function generated the lowest error values. This model can predict the removal behavior very well over the whole range of assayed concentrations because the experimental kinetic data were adequately described by this type of kinetics. In fact, the calculated $q_{e, \text { calc }}$ values agreed very well with the experimental $q_{e, \exp }$ values. Considering this kinetic, an initial phase $(0-2 \mathrm{~h})$ of slow removal of OTC is followed by a quick removal until equilibrium was reached. However, the removal with the dead biomass followed a pseudo-first order kinetics. In some cases, the lowest values of the error functions suggest a sigmoidal model, however, it must be taken into account that the sigmoidal equation (Eq. (6)) corresponds with the equation of the pseudo-first order kinetics (Eq. (3)) when the exponent $\mathrm{c}$ is 1 . Taking into account a 
pseudo-first order kinetics, an initial phase (5-7 h) of rapid OTC removal was followed by a stationary phase in which the amount of removed OTC remained constant.

The sigmoidal kinetics of the OTC removal in the irradiated and inoculated with living biomass tubes suggests that the bioremoval was the main contributor to OTC removal in these assays instead of the photodegradation, and the combined effect of photodegradation and bioremoval improved the process. Thus, for example, in the experiments with an initial OTC concentration of $2.5 \mathrm{mg} \mathrm{L}^{-1}$, the total amount of eliminated OTC was $2.42 \mathrm{mg} \mathrm{L}^{-1}$ after $11 \mathrm{~h}$ using living biomass and photodegradation and considering the parameters obtained with a sigmoidal kinetics (Table 3), whereas with only photodegradation, the amount eliminated was only $0.53 \mathrm{mg} \mathrm{L}^{-1}$. These amounts increased in the highest OTC concentration $\left(15 \mathrm{mg} \mathrm{L}^{-1}\right)$, the total amount eliminated was $13.2 \mathrm{mg} \mathrm{L}^{-1}$, with only $3 \mathrm{mg} \mathrm{L}^{-1}$ due to photodegradation. In the case of dead biomass (Table 3), although the efficiency of the process was lower, also it remained much higher than that obtained by a purely abiotic process. In this case and considering a pseudo-first order kinetics, the total amount eliminated in the initial concentration of $2.5 \mathrm{mg} \mathrm{L}^{-1}$ was $1.09 \mathrm{mg} \mathrm{L}^{-1}$, and $5.07 \mathrm{mg} \mathrm{L}^{-1}$ in the initial concentration of $15 \mathrm{mg} \mathrm{L}^{-1}$ (the amounts eliminated by photodegradation are the same indicated above). Taking into account these results, the combination of photodegradation with the use of living biomass of this microalga would constitute an excellent tool to eliminate OTC. According the results obtained by Leal et al. [17], the time required for $96 \%$ of OTC degradation in aquaculture's waters at $40^{\circ} \mathrm{N}$ latitude in clear sky midwinter days should be $230 \mathrm{~min}$. This time could be further reduced using the microalgal biomass and with the possibility of disposal of the waste products of OTC photodegradation. Moreover, in times or zones of lower irradiation, the microalgal biomass could maintain the efficiency of elimination.

\subsection{Biosorption isotherms}

The equilibrium isotherms are one of the most important data to understand the sorption mechanism. The parameters obtained with the investigated models are listed in Table 8 . The validity of the models was assessed by the error functions listed in Table 1 and the results with these functions are in Table 9. The plots of their non-linear adjustments to these models are shown in Fig. 3. The order of the isotherm best fits the two sets of experimental data in this study was Langmuir > Temkin > Freundlich > Dubinin-Radushkevich. 
Table 8. Isotherm parameters and constants for OTC removal by the biomass of the microalga P. tricornutum.

\begin{tabular}{lllll}
\hline Isotherm Model & Type of biomass & Constants & & \\
\hline Langmuir & & qmax $(\mathrm{mgg}-1)$ & KL(Lmg-1) & \\
& Living & 29.18 & 2.59 & \\
Freundlich & Dead & 4.54 & 0.43 & \\
& & $1 / \mathrm{n}$ & KF(Lmg-1) & \\
& Living & 0.39 & 19.61 & \\
Temkin & Dead & 0.35 & 1.69 & \\
& & $\mathrm{AT}(\mathrm{Lmg}-1)$ & $\mathrm{bT}(\mathrm{Jmol}-1)$ & \\
& Living & 27.72 & 391.52 & $\mathrm{ED}(\mathrm{kJ} \mathrm{Jmol}-1)$ \\
Dubinin Radushkevich & Dead & 3.71 & 2329.81 & 3.26 \\
& & $\mathrm{qmax}(\mathrm{mgg}-1)$ & $\mathrm{BD}(\mathrm{mol} 2 \mathrm{~J}-2)$ & 0.95 \\
\hline
\end{tabular}

Table 9. Values of the error functions for the isotherm models.

\begin{tabular}{|c|c|c|c|c|c|c|c|c|c|c|}
\hline \multirow[t]{2}{*}{ Type of Biomass } & \multirow[t]{2}{*}{ Isotherm Model } & \multicolumn{9}{|c|}{ Error Function } \\
\hline & & $\Delta \mathrm{q}_{\mathrm{t}}(\%)$ & SSE & ARE & HYBRID & EABS & MPSD & $\chi^{2}$ & RMSE & $\mathrm{r}^{2}$ \\
\hline \multirow[t]{4}{*}{ Living Biomass } & Langmuir & 2.36 & 0.97 & 1.86 & 1.25 & 1.93 & 0.03 & 0.05 & 0.49 & 0.998 \\
\hline & Freundlich & 22.85 & 15.09 & 13.79 & 39.79 & 8.67 & 0.26 & 1.24 & 1.94 & 0.97 \\
\hline & Temkin & 4.26 & 2.33 & 3.41 & 3.15 & 2.93 & 0.05 & 0.13 & 0.76 & 0.992 \\
\hline & Dubinin-Radushkevich & 202.69 & 765.18 & 115.57 & 2902.31 & 53.25 & 2.27 & 31.3 & 13.83 & 0.979 \\
\hline \multirow[t]{4}{*}{ Dead Biomass } & Langmuir & 9.16 & 0.15 & 5.84 & 1.86 & 0.81 & 0.1 & 0.07 & 0.19 & 0.987 \\
\hline & Freundlich & 15.78 & 0.47 & 10.29 & 5.59 & 1.43 & 0.18 & 0.19 & 0.34 & 0.959 \\
\hline & Temkin & 10.04 & 0.24 & 7.22 & 2.54 & 1.07 & 0.11 & 0.09 & 0.25 & 0.931 \\
\hline & Dubinin-Radushkevich & 71.59 & 6.25 & 35.96 & 97.89 & 3.97 & 0.8 & 1.71 & 1.25 & 0.997 \\
\hline
\end{tabular}
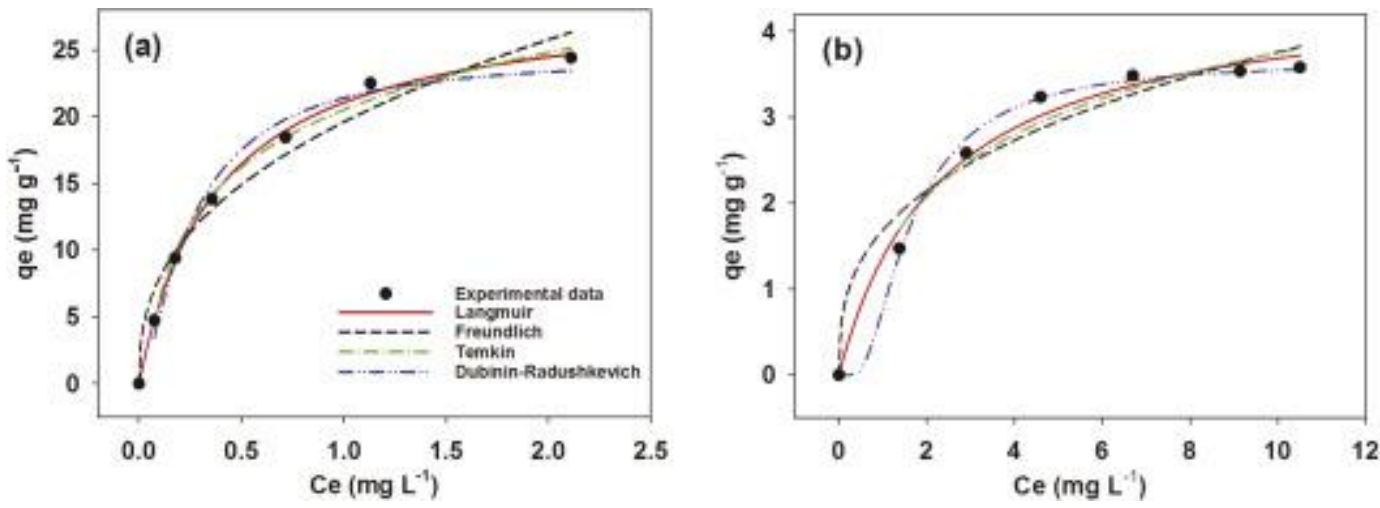

Fig. 3. Equilibrium sorption isotherms of OTC on living (a) and dead (b) biomass of P. tricornutum fitted to Langmuir, Freundlich, Temkin and Dubinin-Radushkevich. 
According to Table 9, Langmuir model showed the lowest values of the error functions. Using this model and considering only the amount eliminated by the biomass, the living biomass of this microalga was able to eliminate $29.18 \mathrm{mg}$ of OTC per gram and the dead biomass $4.54 \mathrm{mg} \mathrm{g}^{-1}$. Clearly, the living biomass was more effective than the dead biomass for OTC removal. Compared to other sorbents (Table 10), the living biomass of this microalga showed a good effectiveness in a short period of time and, in addition, is considered a non-polluting natural material. Other biomaterials used as living biomass for the successful removal of OTC include the biomass of the fungus Pleurotus ostreatus[30] and the bryophyte Fontinalis antipyretica [44]. However, living biomass of the microalga $P$. tricornutum has proven to be more efficient with a higher percentage eliminated and in less time. Obviously, this efficiency increases even more when this biomass is combined with the simultaneous photodegradation caused by the culture of the microalga in presence of light. Although it is difficult to make a comparison, the combination of both technologies could have an efficiency similar to the technologies that use advanced oxidation processes [13], [45] and [46].

Table 10. Comparison of various sorbents used for the removal of OTC.

\begin{tabular}{lllll}
\hline Sorbents & $\mathrm{q}_{\mathrm{m}}\left(\mathrm{mg} \mathrm{g}^{-1}\right)$ & Contact time $(h)$ & {$[\mathrm{OTC}]\left(m g L^{-1}\right)$} & References \\
\hline Na-Kaolinite & $6-13.8$ & 24 & $4.6-234.82$ & {$[47]$} \\
Microscale zerovalent iron (mZVI) & $26.25-34.01$ & 6 & $100-1000$ & {$[48]$} \\
Na-Montmorillonite & $26.71-33.15$ & 24 & $4.6-234.82$ & {$[47]$} \\
Multiwalled Carbon Nanotubes & $30.4-190.2$ & 120 & $1.25-25$ & {$[49]$} \\
Graphene oxide functionalized magnetic particles & 45 & 0.1666 & $10-50$ & {$[50]$} \\
Graphene oxide & 212.314 & 1.5 & $8.33-166.67$ & {$[20]$} \\
Activated Carbon Fiber heated by Microwave (WACF) & $312.50-416.67$ & 12 & $200-800$ & {$[43]$} \\
Living P. tricornutum biomass & 29.18 & 11 & $2.5-15$ & This work \\
\hline
\end{tabular}

The essential features of the Langmuir isotherm can be expressed in terms of a dimensionless constant separation factor $\left(R_{L}\right)$. The $R_{L}$ values were calculated for both biomasses and for each concentration assayed by means of Eq. (8). These values were plotted against the initial OTC concentrations (Fig. 4). This parameter indicates the type of isotherm: unfavorable $\left(R_{L}>1\right)$, favorable $\left(0<R_{L}<1\right)$, linear $\left(R_{L}=1\right)$ or irreversible $\left(R_{L}=0\right)$. All the obtained $R_{\mathrm{L}}$ values for both biomasses were between 0 and 1 , indicating that the sorption of OTC by this microalgal biomass was favorable for all concentrations tested. As the initial concentration increased from 2.5 to $15 \mathrm{mg} \mathrm{L}^{-1}, R_{L}$ decreased from 0.130 to 0.024 in the case of living biomass and from 0.482 to 0.134 for dead biomass. This indicated that sorption was more favorable at higher concentrations. In addition, the values of living biomass were lower and near-zero, which indicates that the process may be considered irreversible. 


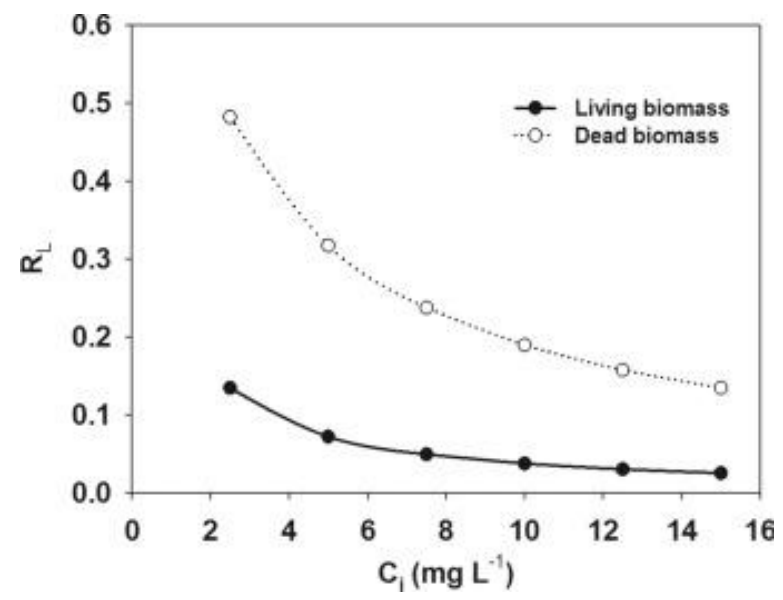

Fig. 4. Variation of separation factor $\left(\mathrm{R}_{\mathrm{L}}\right)$ as a function of initial OTC concentration.

As can be observed in Table 9, the Freundlich isotherm showed worse values of the error functions, although this values are suitable to consider correct the information derived from its constants. The $1 / n$ parameter is known as heterogeneity factor, indicating the degree of non-linearity between solution concentration and sorption. In this way, for a good sorbent, $0.2<1 / n<0.8$; a smaller value of $1 / n$ indicates better sorption and formation of a rather strong bond between the sorbate and sorbent and a material surface more heterogeneous. The values of $1 / n$ obtained in this study ( Table 8 ) indicate favorable sorption properties for both biomasses.

The Temkin constant, $b_{T}$, is related to heat of sorption $\left(\mathrm{J} \mathrm{mol}^{-1}\right)$ which indicates if the sorption reaction is exothermic $\left(b_{T}>1\right)$ or endothermic $\left(b_{T}<1\right)$. The $b_{T}$ values were positive for both biomasses, which indicates that the reaction was exothermic in the concentration range studied. The higher heat of sorption was obtained with the dead biomass and therefore the more exothermic process, which can be explained because the uptake of OTC to the living cells consumes energy.

Finally, Dubinin-Radushkevich isotherm provided the worst fit to the observed data (Table 9). This isotherm predicts the nature of the sorbate sorption onto the sorbent and it is used to calculate the mean free energy of sorption. The calculated value of $E_{D}$ (apparent energy of sorption) is useful for estimating the type of sorption, and if this value is between 8 and $16 \mathrm{~kJ} \mathrm{~mol}^{-1}$, the sorption type can be explained by chemisorption, while values below $8 \mathrm{~kJ} \mathrm{~mol}^{-1}$ indicates a physical sorption process. The values of $E_{D}$ found in this study indicate that the sorption was a physical process.

Most previous works for OTC removal use inorganic compounds as sorbents or physico-chemical treatments; however, although the maximum sorption capacity of this antibiotic on these sorbents can be high in some cases, the risk of using this kind of compounds on the aquatic ecosystems is greater. For this reason, it is important to explore new technologies to remove this pollutant in a less harmful way and without losing efficient. The use of a culture of the microalga $P$. tricornutum as sorbent, it is an alternative and 
promising technology for the removal of OTC from seawater. This result could represent the first step of a phycoremediation technique on a pilot scale, allowing combine two methodologies (bioremediation and photodegradation).

\section{CONCLUSIONS}

This study showed that the living biomass of the microalga Phaeodactylum tricornutum is a useful tool for OTC phycoremediation. The use of living biomass was much more effective and efficient than the same amount of dead biomass. A culture of this microalga (equivalent to $0.4 \mathrm{~g}$ of dry biomass $\mathrm{L}^{-1}$ ) eliminated $97 \%$ of $2.5 \mathrm{mg} \mathrm{L}^{-1}$ of OTC in $11 \mathrm{~h}$. The highest sorption capacity was $29.18 \mathrm{mg} \mathrm{g}^{-1}$. The culture conditions of this microalga allowed to combine bioremediation with photodegradation. Thus, the results obtained in this study demonstrated that living biomass of this microalga was a promising low-cost and an eco-friendly alternative to be used in the OTC removal from seawater solutions.

\section{REFERENCES}

[1] Z.J. Shao, Aquaculture pharmaceuticals and biologicals: current perspectives and future possibilities, Adv. Drug. Deliver. Rev. 50 (2001) 229-243.

[2] A.K. Sarmah, M.T. Meyer, A.B.A. Boxall, A global perspective on the use sales, exposure pathways, ocurrence, fate and effect of veterinary antibiotics (VAs) in the environment, Chemosphere 65 (2006) 725-759.

[3] K. Eguchi, H. Nagase, M. Ozawa, Y.S. Endoh, K. Goto, K. Hirata, K. Miyamoto, H. Yoshimura, Evaluation of antimicrobial agents for veterinary use in the ecotoxicity test using microalgae, Chemosphere 57 (2004) $1733-$ 1738.

[4] G. Dantas, M.O.A. Sommer, R.D. Oluwasegun, G.M. Church, Bacteria subsisting on antibiotics, Science 320 (2008) 100-103.

[5] R. Ueno, A. Kinoshita, J. Wakabayashi, Comparative pharmacokinetics of oxytetracycline in eel and its fate in a closed aquatic environment, Aquaculture 235 (2004) 53-63.

[6] L.A. Reed, T.C. Siewicki, J.C. Shah, The biopharmaceutics and oral bioavailability of two forms of oxytetracycline to the white shrimp, Litopenaeus setiferus, Aquaculture 258 (2006) 42-54.

[7] E.M. Thurman, J.E. Dietze, E.A. Scribner, Occurrence of Antibiotics in Water From Fish Hatcheries, U.S Geological Survey, Washington, DC, 2002.

[8] A.B.A. Boxall, L.A. Fogg, P.A. Blackwell, P. Blackwell, P. Kay, E.J. Pemberton, A. Croxford, Veterinary medicines in the environment, in: Reviews of Environmental Contamination and Toxicology, Springer, New York, 2004, pp. 1-91.

[9] N. Kemper, Veterinary antibiotics in the aquatic and terrestrial environment, Ecol. Indic. 8 (2008) 1-13.

[10] I. Yahiaoui, F. Aissani-Benissad, F. Fourcade, A. Amrane, Removal of tetracycline hydrochloride from water based on direct anodic oxidation $(\mathrm{Pb} / \mathrm{PbO} 2$ electrode) coupled to activated sludge culture, Chem. Eng. J. 221 (2013) 418-425.

[11] C.I. Brinzila, M.J. Pacheco, L. Ciríaco, R.C. Ciobanu, A. Lopes, Electrodegradation of tetracycline on BDD anode, Chem. Eng. J. 209 (2012) 54-61. 
[12] X.-D. Zhu, Y.-J. Wang, R.-J. Sun, D.-M. Zhou, Photocatalytic degradation of tetracycline in aqueous solution by nanosized TiO2, Chemosphere 92 (2013) 925-932.

[13] Y. Liu, X. He, Y. Fu, D.D. Dionysiou, Quantitative assessment on the contribution of direct photolysis and radical oxidation in photochemical degradation of 4-chlorophenol and oxytetracycline, Environ. Sci. Pollut. Res. Int. (2016) 1-9.

[14] H. Pouliquen, R. Delépée, M. Larhantec-Verdier, M.-L. Morvan, H. Le Bris, Comparative hydrolysis and photolysis of four antibacterial agents (oxytetracycline oxolinic acid, flumequine and florfenicol) in deionised water, freshwater and seawater under abiotic conditions, Aquaculture 262 (2007) 23-28.

[15] J.H.O.S. Pereira, V.J.P. Vilar, M.T. Borges, O. González, S. Esplugas, R.A.R. Boaventura, Photocatalytic degradation of oxytetracycline using $\mathrm{TiO}_{2}$ under natural and simulated solar radiation, Sol. Energy 85 (2011) 2732-2740.

[16] B. Tore Lunestad, O.B. Samuelsen, S. Fjelde, A. Ervik, Photostability of eight antibacterial agents in seawater, Aquaculture 134 (1995) 217-225.

[17] J.F. Leal, V.I. Esteves, E.B. Santos, Use of sunlight to degrade oxytetracycline in marine aquaculture's waters, Environ. Pollut. 213 (2016) 932-939.

[18] R. Ocampo-Pérez, J. Rivera-Utrilla, C. Gómez-Pacheco, M. Sánchez-Polo, J.J. López-Penalver, Kinetic study of tetracycline adsorption on sludge-derived adsorbents in aqueous phase, Chem. Eng. J. 213 (2012) 88-96.

[19] M.E. Parolo, M.C. Savini, J.M. Vallés, M.T. Baschini, M.J. Avena, Tetracycline adsorption on montmorillonite: pH and ionic strength effects, Appl. Clay Sci. 40 (2008) 179-186.

[20] Y. Gao, Y. Li, L. Zhang, H. Huang, J. Hu, S.M. Shah, X. Su, Adsorption and removal of tetracycline antibiotics from aqueous solution by graphene oxide, J. Colloid Interface Sci. 368 (2012) 540-546.

[21] P.-H. Chang, Z. Li, J.-S. Jean, W.-T. Jiang, C.-J. Wang, K.-H. Lin, Adsorption of tetracycline on 2:1 layered nonswelling clay mineral illite, Appl. Clay Sci. 67-68 (67) (2012) 158--.

[22] L. Zhang, X. Song, X. Liu, L. Yang, F. Pan, J. Lv, Studies on the removal of tetracycline by multi-walled carbon nanotubes, Chem. Eng. J. 178 (2011) 26-33.

[23] K.-J. Choi, S.-G. Kim, S.-H. Kim, Removal of antibiotics by coagulation and granular activated carbon filtration, J. Hazard. Mater. 151 (2008) 38-43.

[24] G.M. Gadd, Biosorption: critical review of scientific rationale, environmental importance and significance for pollution treatment, J. Chem. Technol. Biot. 84 (2009) 13-28.

[25] A.C. Martins, O. Pezoti, A.L. Cazetta, K.C. Bedin, D.A.S. Yamazaki, G.F.G. Bandoch, T. Asefa, J.V. Visentainer, V.C. Almeida, Removal of tetracycline by $\mathrm{NaOH}$-activated carbon produced from macadamia nut shells: kinetic and equilibrium studies, Chem. Eng. J. 260 (2015) 291-299.

[26] S. Priya, K. Radha, K. Duraivelan, Batch biosorption studies of tetracycline hydrochloride onto unmodified rice straw: equilibrium, Kinetic and Thermodynamic studies, Int. J. Chem. Tech. Res. 6 (2014) 4709-4721.

[27] A.A.S. Al-Gheethi, J. Lalung, E.A. Noman, J.D. Bala, I. Norli, Removal of heavy metals and antibiotics from treated sewage effluent by bacteria, Clean Technol. Environ. 17 (2015) 2101-2123.

[28] M. Ers, an, Removal of tetracycline using new biocomposites from aqueous solutions, Desalin. Water Treat. 57 (2016) 9982-9992.

[29] I. Priyadarshani, D. Sahu, B. Rath, Microalgal bioremediation: current practices and perspectives, J. Biochem. Tech. 3 (2011) 299-304. 
[30] L. Migliore, M. Fiori, A. Spadoni, E. Galli, Biodegradation of oxytetracycline by Pleurotus ostreatus mycelium: a mycoremediation technique, J. Hazard. Mater. 215-216 (2012) 227-232.

[31] R. Shokri Khoubestani, N. Mirghaffari, O. Farhadian, Removal of three and hexavalent chromium from aqueous solutions using a microalgae biomass-derived biosorbent, Environ. Prog. Sustain. Energy 34 (2015) 949-956.

[32] N. Mirghaffari, E. Moeini, O. Farhadian, Biosorption of $\mathrm{Cd}$ and $\mathrm{Pb}$ ions from aqueous solutions by biomass of the green microalga, Scenedesmus quadricauda, J. Appl. Phycol. 27 (2014) 311-320.

[33] S. Lagergren, About the theory of so-Called adsorption of soluble substance, Handlingar 24 (1898) 1-39.

[34] G. Blanchard, M. Maunaye, G. Martin, Removal of heavy metals from waters by means of natural zeolites, Water Res. 18 (1984) 1501-1507.

[35] W.J. Weber, J.C. Morris, Kinetics of adsorption carbon from solutions, J. Sanit. Eng. Div. Proc. 89 (1963) $31-60$.

[36] I. Langmuir, The adsorption of gases on plane surfaces of glass, mica and platinum, J. Am. Chem. Soc. 40 (1918) $1361-1403$.

[37] H.M.F. Freundlich, Over the adsorption in solution, J. Phys. Chem. 57 (1906) 385-470.

[38] M.J. Temkin, V. Pyzhev, Recent modifications to langmuir isotherms acta physiochim, URSS 12 (1940) $217-222$.

[39] M.M. Dubinin, L.V. Radushkevich, Equation of characteristic curve of activated charcoal, Proc. Acad. Sci. Phys. Chem. Sect. USSR 55 (1947) 331-333.

[40] K.R. Hall, L.C. Eagleton, A. Acrivos, T. Vermeulen, Pore- and solid-Diffusion kinetics in fixed-Bed adsorption under constant-Pattern conditions, Ind. Eng. Fund. 5 (1966) 212-223.

[41] I. de Godos, R. Munoz, B. Guieysse, Tetracycline removal during wastewater treatment in high-rate algal ponds, J. Hazard. Mater. 229-230 (229) (2012) 446-449.

[42] D. Zhang, J. Yin, J. Zhao, H. Zhu, C. Wang, Adsorption and removal of tetracycline from water by petroleum coke-derived highly porous activated carbon, J. Environ. Chem. Eng. 3 (2015) 1504-1512.

[43] L. Huang, C. Shi, B. Zhang, S. Niu, B. Gao, Characterization of activated carbon fiber by microwave heating and the adsorption of tetracycline antibiotics, Separ. Sci. Technol. 48 (2013) 1356-1363.

[44] R. Delépée, H. Pouliquen, H. Le Bris, The bryophyte Fontinalis antipyretica Hedw. bioaccumulates oxytetracycline, flumequine and oxolinic acid in the freshwater environment, Sci. Total Environ. 322 (2004) $243-$ 253.

[45] Y. Liu, X. He, X. Duan, Y. Fu, D. Fatta-Kassinos, D.D. Dionysiou, Significant role of UV and carbonate radical on the degradation of oxytetracycline in UV-AOPs: kinetics and mechanism, Water Res. 95 (2016) 195-204.

[46] F. Yuan, C. Hu, X. Hu, D. Wei, Y. Chen, J. Qu, Photodegradation and toxicity changes of antibiotics in UV and UV/H2O2 process, J. Hazard. Mater. 185 (2011) 1256-1263. [47] R.A. Figueroa, A. Leonard, A.A. MacKay, Modeling tetracycline antibiotic sorption to clays, Environ. Sci. Technol. 38 (2004) 476-483.

[47] Ö. Hanay, B. Yıldız, S. Aslan, H. Hasar, Removal of tetracycline and oxytetracycline by microscale zerovalent iron and formation of transformation products, Environ. Sci. Pollut. Res. 21 (2013) 3774-3782.

[48] P. Oleszczuk, B. Pan, B. Xing, Adsorption and desorption of oxytetracycline and carbamazepine by multiwalled carbon nanotubes, Environ. Sci. Technol. 43 (2009) 9167-9173.

[49] Y. Lin, S. Xu, J. Li, Fast and highly efficient tetracyclines removal from environmental waters by graphene oxide functionalized magnetic particles, Chem. Eng. J. 225 (2013) 679-685. 